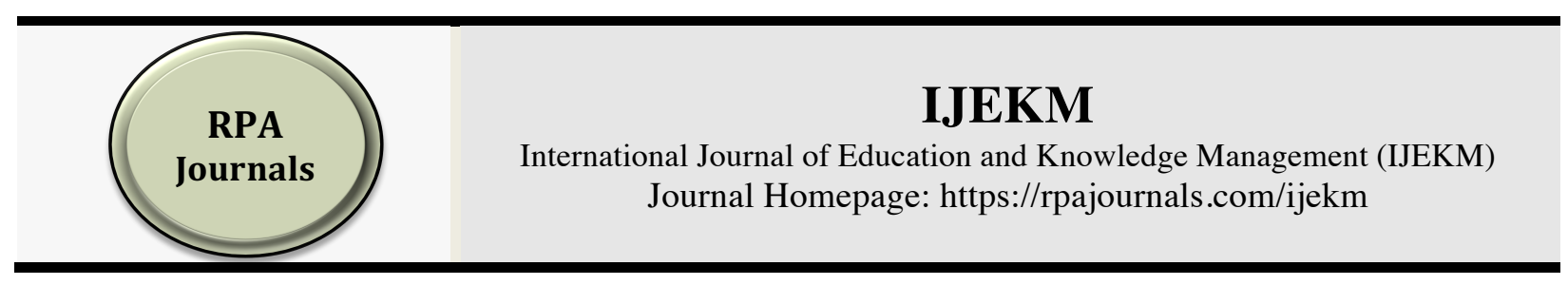

\title{
Innovative Management Practices towards Waste Reduction in Food Service Establishments of Klang Valley in Malaysia
}

\author{
Ahasanul Haque*1 \\ SMH Kabir ${ }^{2}$ \\ Mohammad Moshiur Rahman ${ }^{3}$ \\ International Islamic University Malaysia (IIUM), Malaysia
}

\begin{abstract}
Every year about billion tons of foods are wasted globally. The problem of food waste is increasingly attracting the attention of the issues related to healthy and sustainable food. Food waste also becoming a significant issue for the socio-economic aspects of Malaysia through environmental degradation. Therefore, it is required to determine the innovative management practices that are intended to reduce the food wasted during the different stages of the supply chain: from the first steps in the production and storage up to the product cooked and ready to be consumed by customers. The purpose of this study was to determine the innovative food management practices that can contribute to the prevention or reprocessing of food waste in foodservice establishments. The study has been conducted by qualitative content analysis. An individual depth interview method has been applied to collect data from six food supply chain managers in different restaurants and cafeterias operating in Klang valley area of Malaysia. Data has been analyzed systematically using Nvivo version 12 computer program. The study found that there is a significant lack of priorities in management practices regarding food waste reduction and knowledge gap by the foodservice operators in line with sustainable food consumption. Such a study is necessary to come up with creative ideas on how food waste can be reduced in the retail foodservice industry. Reducing food waste and implementing innovative food waste management practices can be beneficial for any member of the global ecological community.
\end{abstract}

Keywords: Sustainable; Food, Waste, Management, Reduction

**Corresponding author: Ahasanul Haque; E-mail: ahasanul@iium.edu.my

DOI: https://doi.org/10.37227/ijekm-2020-02-10

\section{Introduction}

The problem of food waste is increasingly attracting interest within the public and academic domains. This is because of the vastness of the issue and to the expanding consideration of the issues identified with healthy and sustainable consumable. Subsequently, it is plausible to watch an expanding number of activities that are planned to lessen the food wasted during the various phases of the inventory network: from the initial phases in the creation and capacity up to the item cooked and ready to be taken by clients. Wasting of food remains an odd thing to rise repeatedly and various actions has been taken to solve this issue. The main objective of this study is to identify inventive management practices that can contribute to the prevention or recycling of food waste in food service establishments and to evaluate food service managers' actions concerning the necessity of various food waste innovations. 
High food waste generation in Malaysia that reached up to 15, 000 tons per day assign for major problems towards environment, economy and social aspect (Firdaus et al., 2018). It has been demonstrated that wasting of food results ecological deprivation (EC, 2010; Scholz, 2013), raises moral concerns (Nellman et al., 2009) and has a monetary loss (Quested and Johnson, 2009). These three interlinked outcomes are turning into a significant problem for our general public on the grounds that the amount of food waste has expanded with time; this expanding measure of food waste happens at each stages of the food inventory network (Göbel et al, 2012). It is very much clear that a food waste reduction plan and specifically a waste management practice which does not consider social and environmental concerns will fail to succeed (Heikkilä et al., 2016). This can be a barrier for successful implementation of food waste reduction program. Therefore, such study is critical to better understand how food waste mitigation can be improved in the retail food service establishments so that food does not waste, and it can be reused or recycled.

\section{Literature Review}

Wasting of food is an environmental, financial and social issue. Globally, about 1.3 billion tons of food was being thrown to the waste bin every year (FAO, 2013). It indicates to a major portion of the total food produced (Lundqvist et al., 2008; Parfitt et al., 2010). This problem is very much common in developed nations (Buzby and Hyman, 2012). There are about 842 million people in poor countries embracing hunger continuously (FAO, 2013). This is a clear consequence of imbalance which brings up burning issues about if wasting of food can be reduced throughout the food supply chain (Curtis et al. 2016; Martinez-Sanchez et al. 2016; Muriana, 2017; WilewskaBien et al., 2016). The foodservice business presently utilizes a bigger number of individuals than any single other retail business (Euromonitor International, 2016) and serves billions of dishes consistently (Gössling et al., 2011). Accordingly, they have a basic job in the worldwide food supply chain. There is solid evidence that a significant amount of food is being wasted during preparation, preserving, served or on the ground that the foods can't be reused (Betz et al., 2015; Hall and Gössling, 2013; Silvennoinen et al., 2015). Managing the food waste has in this way turned into a key need, alluding to every one of the exercises identified with abstaining from, lessening or reusing waste, all through the creation and utilization chain of food (Papargyropoulou et al., 2016).

Losses of food categorized into five stages, storage losses, preparation losses, serving losses, plate waste, and leftovers (Engström \& Carlsson-Kanyama, 2004; Haque, Sarwar, Yasmin, Tarofder, \& Hossain, 2015). In Sweden, from the $100 \%$ of waste, $60 \%$ were serving losses, $25 \%$ plate waste and $10 \%$ preparation losses (Betz et al., 2015). Another study revealed that between $11 \%$ and $13 \%$ of food waste is plate waste being the largest source of loss in Sweden (Pirani \& Arafat, 2014). In UK, 65\% of food waste is fallen under preparation waste, $30 \%$ as customer's plate waste, and 5\% as spoilage by clients (Pirani \& Arafat, 2014). In Finland, 19\% of the total food produced goes wasted, where $6 \%$ of its kitchen waste, $5 \%$ service waste and $7 \%$ leftovers by clients (Pirani \& Arafat, 2014). In USA, around $40 \%$ of the food goes uneaten, and most of it becomes landfills across the country (Gunders, 2012). In Latin America, where appetite influences $8 \%$ of its populace, and where with the food lost distinctly at the retail level 30 million individuals could be sustained, waste reduction of food ends up the key, not just for its effect on the landfills of the district, and the administration of waste age, yet for its effect in the business of the individuals (FAO, 2017a). In the following Table 1, the main suggested solutions given by previous researchers for food waste reduction are summarized. 
Table 1. Various food waste reduction strategy (Lagorio, Pinto \& Golini, 2018)

\begin{tabular}{|l|l|}
\hline \multicolumn{1}{|c|}{ Authors } & \multicolumn{1}{c|}{ Suggested strategy } \\
\hline Bonomi et al., 2016 & $\begin{array}{l}\text { Providing unused food to poor people, engaging different } \\
\text { stakeholders including government officials, NGOs }\end{array}$ \\
\hline Byker et al., 2014 & Reducing food amount, asking for customer's choices \\
\hline Falasconi et al., 2015 & $\begin{array}{l}\text { Applying less packaging for sweet and salty foods, restructuring } \\
\text { food menu, providing training to staffs for better tasty food } \\
\text { preparation, spending more time on raw material procurement }\end{array}$ \\
\hline Jungbluth et al., 2016 & Emphasizing on better supply chain and food menu composition \\
\hline Martins et al., 2014 & $\begin{array}{l}\text { Reducing food amount, providing training to staffs for better } \\
\text { tasty food preparation }\end{array}$ \\
\hline $\begin{array}{l}\text { Rodriguez-Tadeo et al., } \\
\text { 2014 }\end{array}$ & $\begin{array}{l}\text { Reducing food amount, providing training to staffs for better } \\
\text { tasty food preparation }\end{array}$ \\
\hline Silvennoinen et al., 2015 & $\begin{array}{l}\text { Restructuring food menu, reducing food amount, emphasizing on } \\
\text { better supply chain and food menu composition }\end{array}$ \\
\hline Toth et al., 2017 & Providing training to staffs for better tasty food preparation \\
\hline
\end{tabular}

While the expression "sustainable development" is repeatedly utilized by government officials, analysts or the general population, its definition isn't complete till now. Griggs et al (2013, pp.306) proposed a definition of sustainable development as the "Development that meets the needs of the present while safeguarding Earth's life-support system, on which the welfare of current and future generations depends". So far the most perceived, yet in addition presumably also the most reprimanded, meaning of sustainable development was the one from the Brundtland report (Brundtland, 1987, pp. 40) which stated that "Development that meets the needs of the present without compromising the ability of future generations to meet their own needs". A quarter century of research has passed, but the definition of sustainable development remains the same. The issue of food waste is considered as a wasteful utilization of environmental administrations and its supportive networks (Nelleman et al, 2009). For example, the generation, transportation and handling of food require a lot of water, land, minerals and vitality. Every one of these requirements depends on biological system administrations which are utilized futile if food isn't eaten finally by the consumers. So, the decrease of food waste in food establishments (restaurants, cafeterias, canteens) and more specifically in the whole food production network will depend on the cognitive behaviour of respected stakeholder actions. In order to reduce waste of food, most of the previous studies focused on identifying human behaviour during cooking process, consumption and waste management practices (Lundie and Peters, 2005) which are also followed in this research.

Porpino (2016) stated that behavioral research can be a great help in order to know how to frame actions and change behaviour. More data concerning food waste together with empirical research will help to understand the concept better. He created the theoretical framework shown below (Figure 1). Of course, the content must be adapted for it to fit with this study (Food waste in canteen and cafeteria instead of household). This framework could be very handy for future researchers as well. Emotions and communication initiatives can be investigated through experiments and cross-sectional research, retail and marketing stimuli and consumer culture can be researched through ethnographic oriented research. The measurement validation for this study is the amount of food wasted at canteens and cafeterias instead of food waste in households. Then, behavioral economics can be applied (why do people sometimes make irrational decisions? Why

International Journal of Education and Knowledge Management (IJEKM) 
and how does their behaviour not follow the predictions of economic models? (Investopedia, 2017)), which - hopefully - will lead to the desired scenario: sustainable consumption.

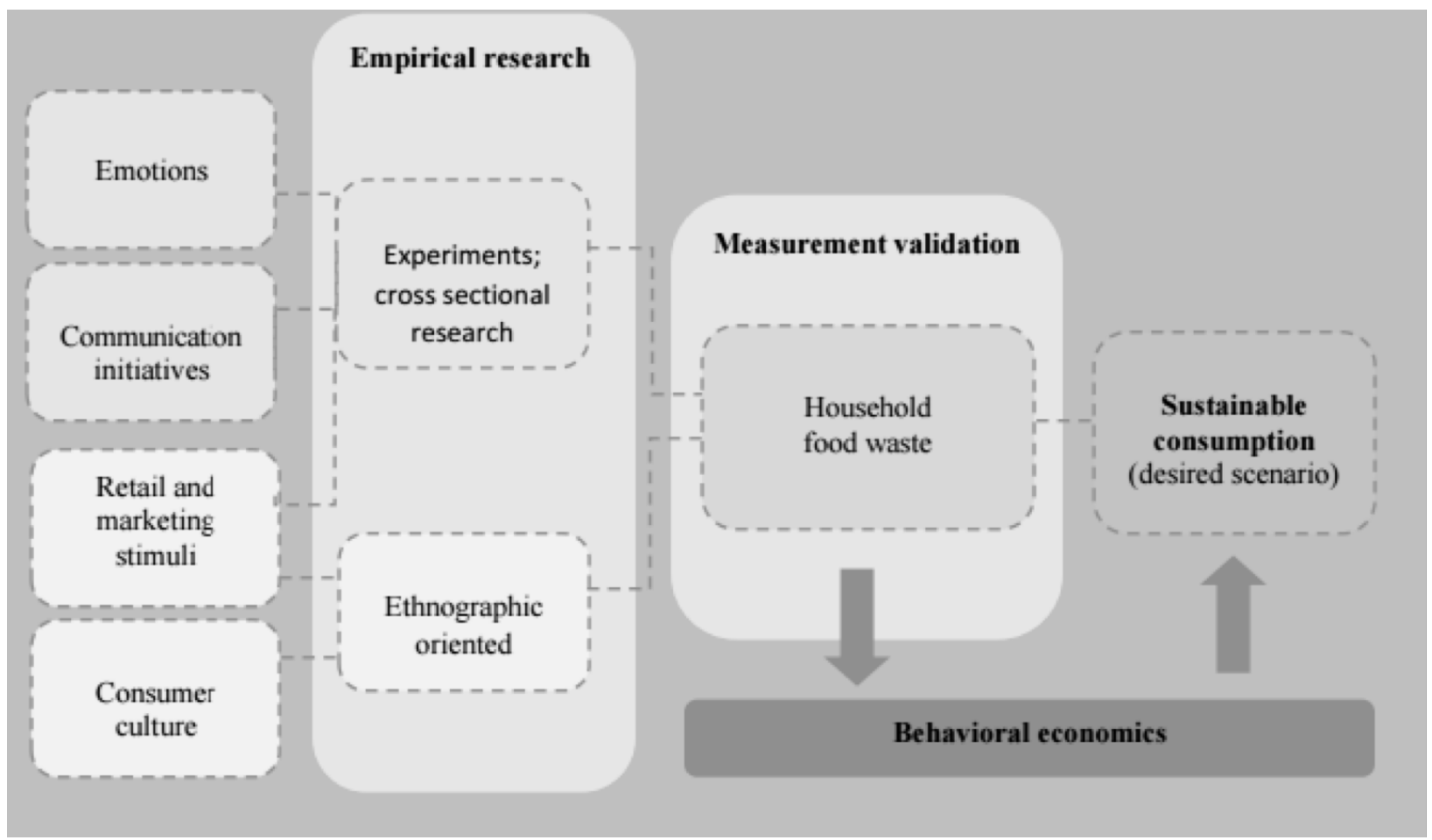

Figure 1. Research Framework on Food Waste (Porpino, 2016)

\section{Methods}

In order to identify the innovative management practices for mitigating food waste, a qualitative method has been employed in this study. According to Somekh \& Lewin (2005), methodology of human behaviour is the interpretive paradigm, which recognizes subjectivity while implicitly adopting the perspective of the sociology of regulation. Based on face-to-face interviews with food service providers in canteens and cafeterias located at Klang valley area in Malaysia, the study offered a discussion of possible management practices in food waste and the range of incremental to radical innovations that can be possible to be found in the food sector. Criteria for sample selection were that the respondents had food service business and know about the whole supply chain network of food delivery service. The participants were selected using non-probabilistic convenience sampling technique. The members of the sample were communicated directly and agreed with them for the interview on the appropriate date and time. After taking consent from the participants, the interviews were conducted with semi-structured questionnaires. It is then being written literally into transcriptions. The research was limited to a number of six interviews and was held from 1 to 5 October 2019. The questions were clearly open-ended, giving the participants the freedom to express their opinion and to clarify their point of view comfortably (Islam, Hunt, Jantan, Hashim \& Chong, 2019). After that, Nvivo computer program (version 12) has been used to analyze the data (Bazeley \& Jackson, 2013).

\section{Results and Discussion}

From the interviews, demographic information presented in Table 2 indicates the validity of certain age group and job role of the respondents which were ideal for the subject matter studied. The respondents were Malaysian as well as foreigner as the food items were from different parts of the world based on customers visiting their premises. Though, the questionnaires were semi-structured 
and open ended, most of the respondents answered very straight forward leaving the interview within short period of time. The average time of interview taken was 20 minutes.

Table 2 Demographic Information of Respondents

\begin{tabular}{|c|c|c|c|c|c|c|}
\hline Variable & $\begin{array}{c}\text { Interview } \\
\mathbf{1}\end{array}$ & $\begin{array}{c}\text { Interview } \\
\mathbf{2}\end{array}$ & $\begin{array}{c}\text { Interview } \\
\mathbf{3}\end{array}$ & Interview 4 & Interview 5 & $\begin{array}{c}\text { Interview } \\
\mathbf{6}\end{array}$ \\
\hline Gender & Male & Male & Male & Male & Male & Male \\
\hline Age (Years) & $41-50$ & $41-50$ & $41-50$ & $31-40$ & $31-40$ & $31-40$ \\
\hline Designation & Owner & Co- owner & Co- owner & Owner & Master Chef & $\begin{array}{c}\text { Master } \\
\text { Chef }\end{array}$ \\
\hline Company & $\begin{array}{c}\text { Rezki Food } \\
\text { Sdn Bhd }\end{array}$ & Ali Cafe & $\begin{array}{c}\text { Somalian } \\
\text { Food Court }\end{array}$ & $\begin{array}{c}\text { Algerian } \\
\text { Food Court }\end{array}$ & $\begin{array}{c}\text { Yemen Food } \\
\text { Corner }\end{array}$ & $\begin{array}{c}\text { Al- Qadar } \\
\text { Food Sdn. } \\
\text { Bhd }\end{array}$ \\
\hline Experience & 3 & 17 & 14 & 7 & 4 & 5 \\
\hline
\end{tabular}

In this research, all the interviews were transcribed and imported separately before analyzed them in Nvivo. Total 3162 words, 289 paragraphs and 74 text references were found in 6 interview transcripts presented in Table 3.

Table 3. Summary of Total Transcripts

\begin{tabular}{|c|c|c|c|c|c|}
\hline Interview & $\begin{array}{c}\text { Total Words } \\
\text { in Source }\end{array}$ & $\begin{array}{c}\text { Total } \\
\text { Paragraphs in } \\
\text { Source }\end{array}$ & $\begin{array}{c}\text { Number of } \\
\text { Nodes Coding } \\
\text { Source }\end{array}$ & $\begin{array}{c}\text { Coded } \\
\text { Percentage of } \\
\text { Source }\end{array}$ & $\begin{array}{c}\text { Number of } \\
\text { Text } \\
\text { References }\end{array}$ \\
\hline Transcript 1 & 589 & 50 & 3 & 0.3193 & 16 \\
\hline Transcript 2 & 582 & 49 & 3 & 0.3306 & 13 \\
\hline Transcript 3 & 552 & 48 & 3 & 0.2799 & 12 \\
\hline Transcript 4 & 480 & 47 & 3 & 0.1933 & 11 \\
\hline Transcript 5 & 484 & 47 & 3 & 0.1833 & 10 \\
\hline Transcript 6 & 475 & 48 & 3 & 0.1925 & 12 \\
\hline
\end{tabular}

From the word cloud presented in Figure 2, it can be seen that "food", "try" and "depends" are the three most spoken words in the interviews. From the tree map (Figure 3) of words, it shows the mapping of words in a form of a tree. 


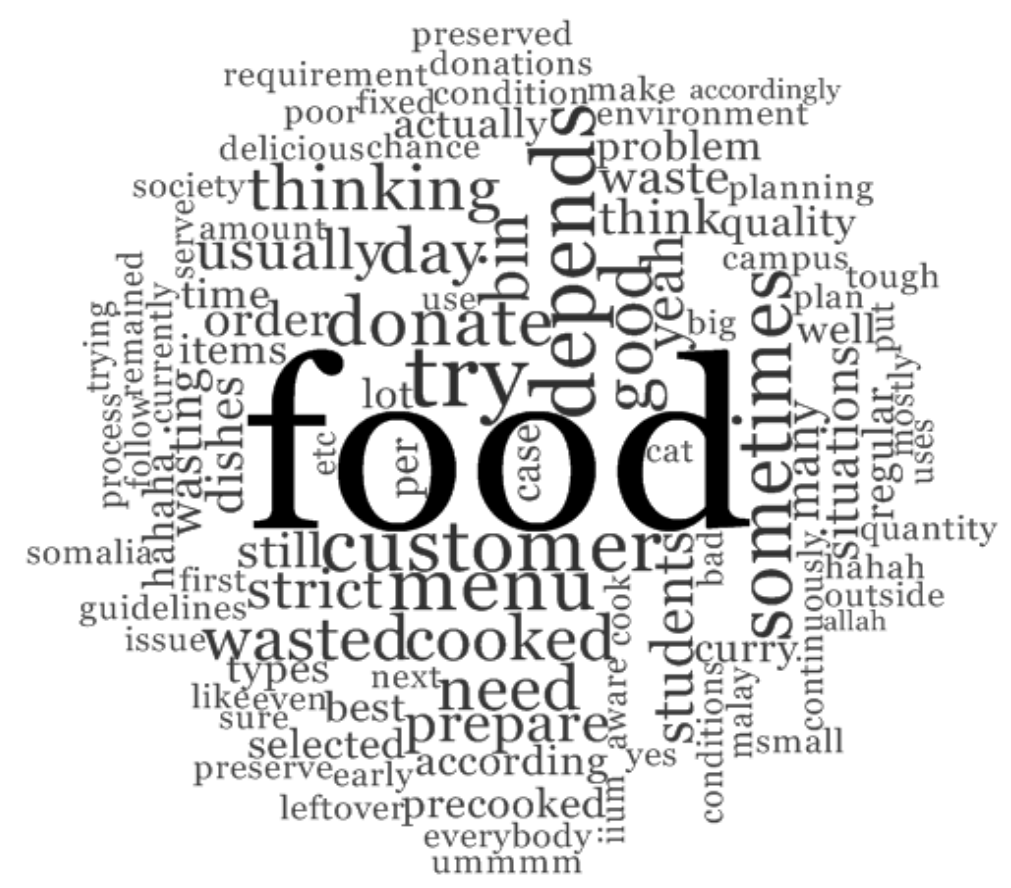

Figure 2. Word Cloud

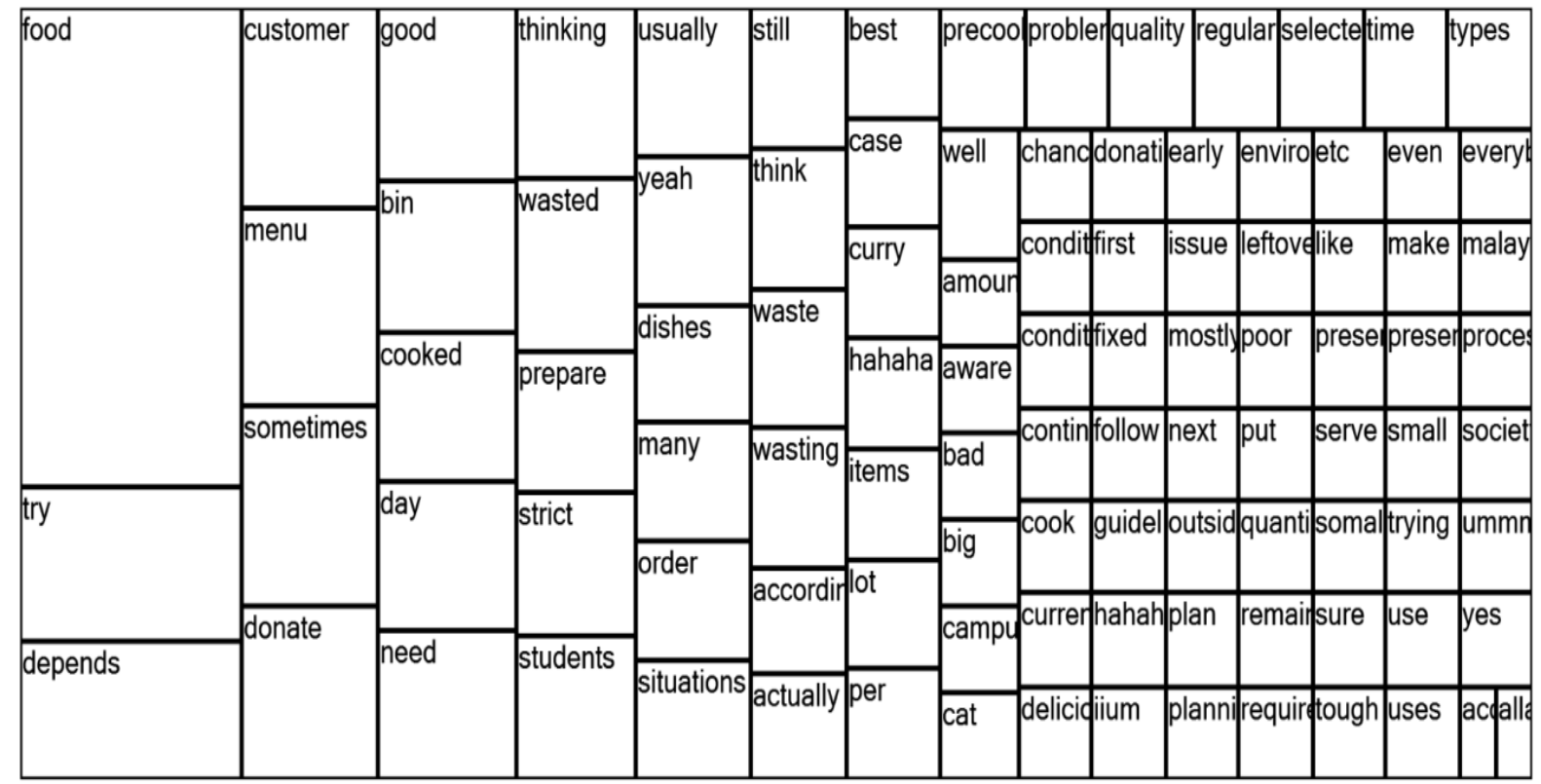

Figure 3. Tree Map

From the cluster analysis diagram (Figure 4), the category of words clustered in each category has been shown. 


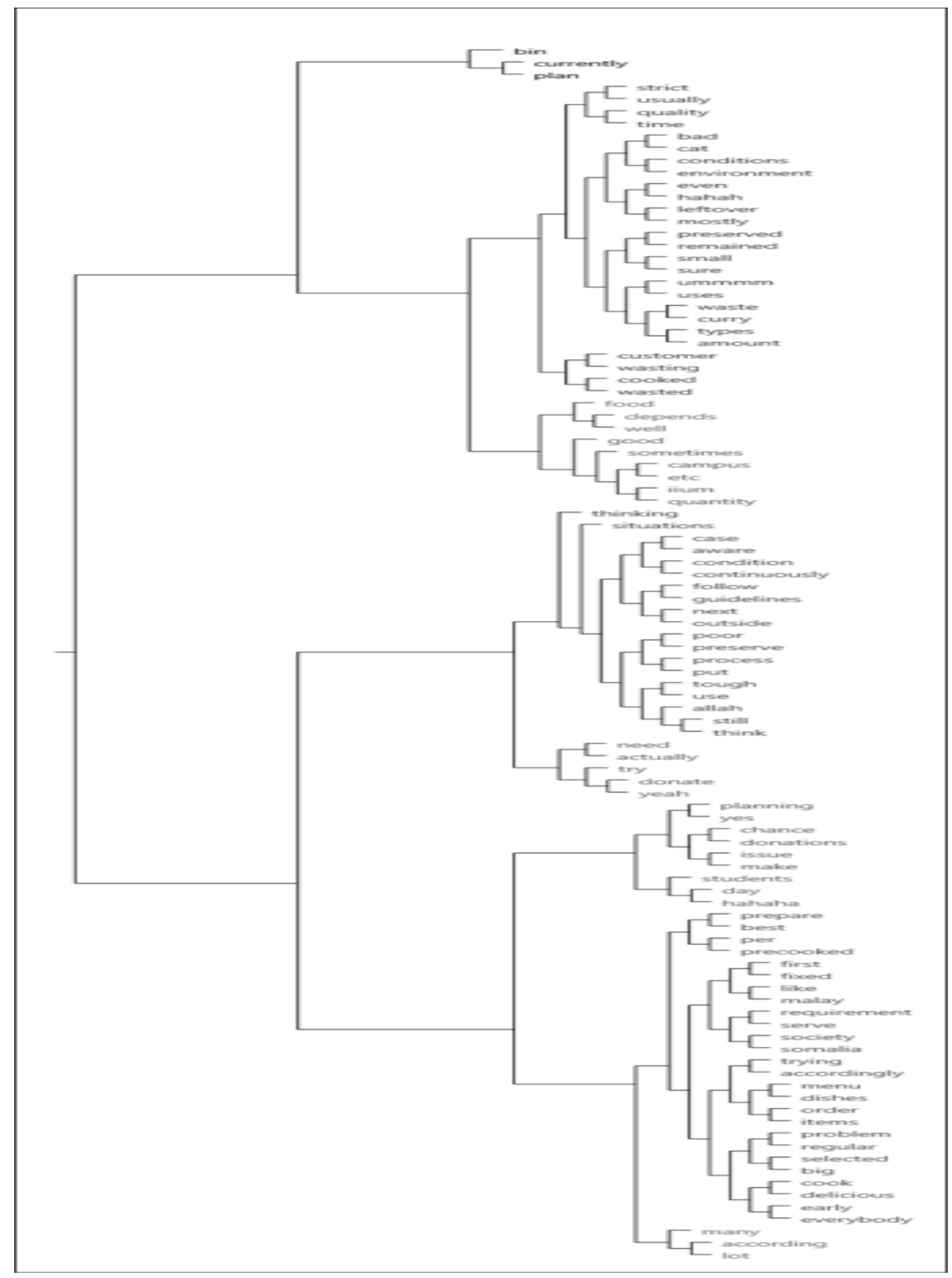

Figure 4. Cluster Analysis Report 
Total 3162 words were being coded from all 6 transcripts. These codes were then recoded and grouped under certain categories. Each category has been then labelled and considered as theme. From these themes, it can be seen that, "Food Service" being the highest spoken theme where "Food Waste" and "Waste Reduction Management Practice" are an integral part. The group query report (Figure 5) also shows the relationships among derived themes and respondents. The themes which have been developed from the codes are indexed in Table 4 according to their coded reference. 1 (one) being the highest reference and 3 (three) being the lowest reference among the derived themes.

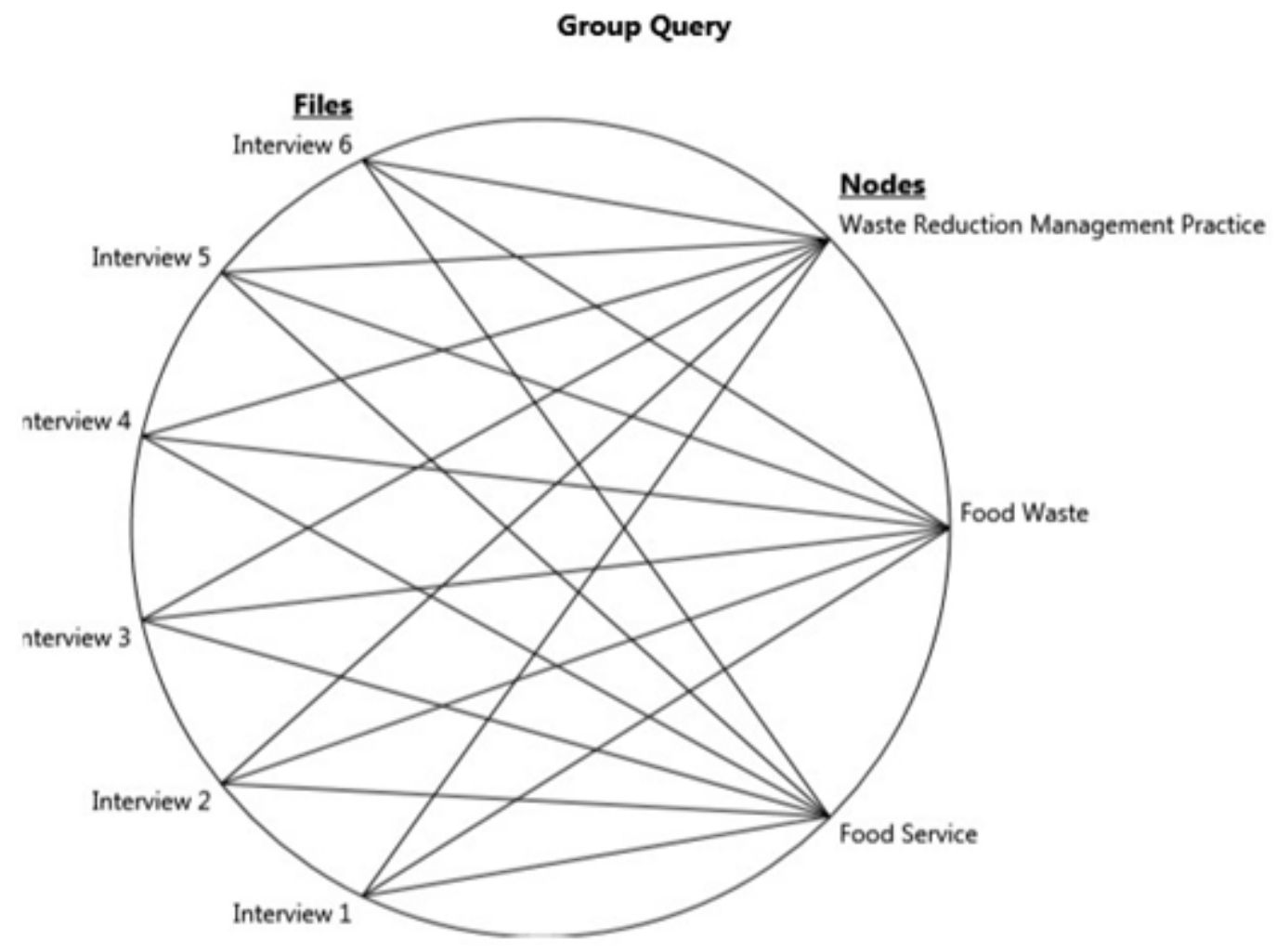

Figure 5. Group Query Report

Table 4. Themes-Hierarchy

\begin{tabular}{|c|c|}
\hline Hierarchy & Themes \\
\hline 1 & Food Waste Reduction Management Practices \\
\hline 2 & Food Waste \\
\hline 3 & Food Service \\
\hline
\end{tabular}

There were strong inter-relationships among the themes derived from the interviews (Creswell, 2007). From the six themes it can be said that, food service is a basic function requires waste management mitigation plan in the service operators to ensure waste reduction practices towards sustainable food consumption. This statement clearly identifies the similarity of what the research objective was in this study. Most of the respondents agreed upon having many dishes (10 to 20) 
which were pre-cooked and served to the customers as a fixed menu for every day except Friday and weekends. Hence, one of the interviewees said:

"Actually, there are many dishes that need to order first to prepare. Other than that, most of the food are precooked and deliver according to the customer order."

On Friday and weekends, they prepare more dishes based on the frequency of customers. Every day in the early morning, they decide on the menu for that day. Hence, one of the interviewees said:

"It fixed 15 to 20 menu per day or more, but we decide in the morning."

Regarding food waste, all the respondents were agreed upon having wasted of food done by customers mainly, sometimes it was done by themselves due to unavoidable circumstances. They were reluctant about talking about their own mistakes which is very normal. Hence, one of the interviewees said:

"Well ah...it depends on the situations. Most of the it the customer who wasted most and some time it is us who is responsible for wasting of food as you said cooked item burnt, leftover and others."

While answering the question "what they do about the food which is in the process of going bad or not consumable anymore", most of the respondents said that they through it to the waste bin and sometimes give it to the cats. To reduce wasting of food, it is possible to process and reuse it, for example, providing food wastage to animals, providing it to the soil as fertilizers or in an organic energy source. Hence, one of the interviewees said:

"Depends on conditions...Most of the time preserved when it is remained good. Bad food usually uses for cat food. hahah..."

While answering the question about what type of food usually get wasted, all the respondents agreed upon curry items, vegetables and salad items. Whether they want to donate any un-served/unused food to the poor people, all of them were pretty much positive about giving food donation and raised their religious sentiment. But it requires some planning, as one of the interviewees said:

"No, we don't have chance to donate. We are planning to make the donations."

All the respondents agreed upon having some plan to think which can reduce food waste by either the customer or their staffs. They do not have adequate knowledge about how to reduce food waste, but they were very much interested about discussing food waste reduction plan. This is a clear indication of the gap between the understandings of the food service operators and their management practices. But all the respondents were agreed upon having food waste is a regular issue which needs to be solved. Hence, one of the interviewees said:

"Yes! Of course. A lot of food is being wasted daily that is not good at all."

It is being proved that the presence of two focused objectives are encountered in this study by involving the food service managers as the main stake holder, identifying their current management practices for waste reduction, their knowledge gap and future plan for innovation elaborates the necessity of such research phenomena. Reducing food waste and implementing innovative food waste management practices can be beneficial to the food service business owners 
for several reasons. Firstly, in doing this, the restaurant owner can demonstrate corporate social responsibility and thus improve their image. Secondly, wasting less as a result of less food being ordered can result in saving the owner's financial resources.

The restaurants where the interviews were conducted located in Klang valley of Malaysia. There are no studies found similar to this research setting. But the themes derived from this study are supported by previous researchers. Food waste originates from household kitchens, commercial kitchens, canteens, cafeterias and restaurants (Thyberg and Tonjes, 2016; Chen et al., 2017). The management practices in the respected food outlets where this study has been conducted are not clearly following the standard operating procedures (SOPs). It proves that food waste is not only a social, economic or environmental issue, it is also an ethical concern which needs to be extremely measured (Thi, Lin, \& Kumar, 2016). Therefore, innovative ways of reducing food waste need to be implemented.

\section{Recommendation}

Among different types of environmental waste, food waste should be addressed by managements in all parts of the world and should be placed in a position of relevance according to local legislation. Following innovative techniques and activities can be set up to reduce food waste in the food service establishments, (1) increasing of staff consciousness of the issue through compensating explicit activities, and focal point of eateries on their waste sums and their inceptions, (2) incorporating menu building, action based costing, following food waste, decrease of plate size, clients fining, donation of leftover foods, (3) bio-treatment choices, for example, anaerobic processing and fertilizing the soil, conveyance checking to confirm for contaminants, harmed bundling, checking expiry date; locally sourcing items, (4) first in first out (FIFO) approach in stock, stockpiling practices to enable air to arrive at leafy foods, evasion of over cutting during planning, and minimization of starters parcels.

\section{Limitation and Implication for Further Research}

Every study encounters some limitations. In this research, the main limitation was sample size. Due to unavailability of respondents in the study settings, the number of interviews has been limited to six restaurants. Further research on this area should undertake more sample size to facilitate the results. The English language spoken proficiency of the respondents were also a barrier during interviews taken. As a result, the interviews were not in-depth. Future researchers should focus on the length of interview. The content analysis will be more qualitative if the interviews are in-depth. Usually the master chefs are from different parts of the world based on the type of cuisines. Therefore, it will be easier for future researchers to interact with the master chefs if any language translators are occupied.

\section{Conclusion}

Malaysia is notable for its incredible food culture. There are decent varieties and taste of Malaysian food in South East Asia. Shockingly, the food culture is additionally transforming into a culture of waste. Food security and food safety are two most challenging things for Malaysians in recent years. Wasting of food undesirably influences the accessibility of food to other people. When more than $33 \%$ of universally created food is left-over, unluckily, there are 868 million individuals who lives with starvation. There is no model for food waste which fits all situations. Therefore, special measures to address it ought to be required for every individual circumstance. The study demonstrated in this research shows the possibilities to implement an effective initiative for the reduction of food waste in canteens and cafeterias with leveraging on stakeholders' involvement. 


\section{References}

Betz, A., Buchli, J., Göbel, C., \& Müller, C. (2015). Food waste in the Swiss food service industryMagnitude and potential for reduction. Waste Management, 35, 218-226.

Betz, A., Buchli, J., Göbel, C., \& Müller, C., (2015). Food waste in the Swiss food service industry - Magnitude and potential for solution. Waste Management, vol. 35, pp. 218-226.

Brundtland report, 1987. Report of the World Commission on Environment and Development. Our Common Future. Oxford: Oxford University Press. ISBN 019282080X.

Buzby, J.C., \& Hyman, J. (2012). Total and per capita value of food loss in the United States. Food Policy, 37(5), 561-570.

Chen, H., Jiang, W., Yang, Y., Yang, Y., \& Man, X. (2017). State of the art on food waste research: a bibliometrics study from 1997 to 2014. Journal of Cleaner Production, 140, $840-846$.

Curtis, K.R., \& Slocum, S.L. (2016). The role of sustainability certification programs in reducing food waste in tourism. Journal of Developments in Sustainable Agriculture, 11(1), 1-7.

EC., 2010. Final Report - Preparatory Study on Food Waste Across EU27, European Commission. DG ENV - Directorate C, Brussels, Belgium.

Engström, R. \& Carlsson-Kanyama, A., (2004). Food losses in food service institutions: Examples from Sweden. Food Policy, vol. 29 (3), pp. 203-213.

Euromonitor International (2016). Consumer Food service.

FAO, (2017a). Pérdidas y desperdicios de alimentos en América Latina y el Caribe. FAO Regional Office for Latin America and the Caribbean.

Firdaus, A. R. M., Samah, M. A. A., \& Hamid, K. B. A. (2018). CHNS analysis towards food waste in composting. Journal CleanWAS, 2(1), 06-10.

Food and Agriculture Organisation of the United Nations (FAO), International Fund for Agricultural Development (IFAD), United Nations World Food Programme (WFP) (2013).

The State of Food Insecurity in the World 2013. The multiple dimensions of food security.

FAO: Rome (Italy).

Fork to Landfill. Natural Resources Defense Council, IP: 12-06-B.

Göbel, C., Teitscheid, P., Ritter, G., Blumenthal, A., Friedrich, S., Frick, T., Grotstollen, L., Möllenbeck, C., Rottstegge, L., Pfeiffer, C., Baumkötter, D., Wetter, C., Uekötter, B., Burdick, B., Langen, N., Lettenmeier, M. \& Rohn, H. (2012). Reducing Food Waste Identification of causes and courses of action in North Rhine- Westphalia. Abridged version, University of Applied Sciences Münster, Institute for Sustainable Nutrition and Food Production - iSuN, Münster, Germany.

Gössling, S., Garrod, B., Aall, C., Hille, J., \& Peeters, P. (2011). Food management in tourism: Reducing tourism's carbon 'foodprint'. Tourism Management, 32(3), 534-543.

Griggs, D., Stafford-Smith, M., Gaffney, O., Rockström, J., Öhman, M.C., Shyamsundar, P., Steffen, W., Glaser, G., Kanie, N., Noble, I., 2013. Sustainable development goals for people and planet. Nature 495, 305-307.

Gunders, D., (2012). Wasted: How America is Losing Up to 40 percent of Its Food from Farm to

Hall, C.M., \& Gössling, S. (2013). Sustainable culinary systems: Local foods, innovation, and tourism \& hospitality. London: Routledge.

Haque, A., Sarwar, A., Yasmin, F., Tarofder, A. K., \& Hossain, M. A. (2015). Non-Muslim consumers' perception toward purchasing halal food products in Malaysia. Journal of Islamic Marketing. 6(1), pp. 133-147

Heikkilä, L., Reinikainen, A., Katajajuuri, J. M., Silvennoinen, K., \& Hartikainen, H. (2016). Elements affecting food waste in the food service sector. Waste Management, 56, 446-453.

Islam, M. A., Hunt, A., Jantan, A. H., Hashim, H., \& Chong, C. W. (2019). Exploring challenges and solutions in applying green human resource management practices for the sustainable workplace in the ready-made garment industry in Bangladesh. Business Strategy \& Development.3(1), 1-12. 
Lagorio, A., Pinto, R., \& Golini, R. (2018). Food waste reduction in school canteens: Evidence from an Italian case. Journal of Cleaner Production, 199, 77-84.

Lundie, S., \& Peters, G. M, 2005. Life cycle assessment of food waste management options. J. Clean. Prod., 13(3), 275-286.

Lundqvist, J., de Fraiture, C., \& Molden, D. (2008). Saving water: from field to fork-curbing losses and wastage in the food chain. SIWI Policy Brief. Stockholm, Sweden: SIWI.

Martinez-Sanchez, V., Tonini, D., Møller, F., \& Astrup, T.F. (2016). Life-cycle costing of food waste management in Denmark: importance of indirect effects. Environmental Science \& Technology, 50(8), 4513-4523.

Muriana, C. (2017). A focus on the state of the art of food waste/losses issue and suggestions for future researches. Waste Management 68, 557-570.

Nelleman, C., MacDevette, M., Manders, T., Eickhout, B., Svihus, B. \& Prins, A.G., 2009. The environmental food crisis - the environment's role in averting future food crises. United Nations Environment Programme (UNEP), Norway.

Papargyropoulou, E., Wright, N., Lozano, R., Steinberger, J., Padfield, R., \& Ujang, Z. (2016). Conceptual framework for the study of food waste generation and prevention in the hospitality sector. Waste Management, 49, 326-336.

Parfitt, J., Barthel, M., \& Macnaughton, S. (2010). Food waste within food supply chains: quantification and potential for change to 2050. Philosophical Transactions of the Royal Society of London B: Biological Sciences, 365(1554), 3065-3081.

Pirani, S., \& Arafat, H., (2014). Solid waste management in the hospitality industry: A review. Journal of Environmental Management, 146, pp. 320-336.

Porpino, G. (2016) Household food waste behavior: avenues for future research: Brazilian Agricultural Research Corporation.

Quested, T., Johnson, H., 2009. Household food and drink waste in the UK The State of Food Insecurity in the World, The multiple dimensions of food security, 2013. Food and agriculture organization of the United Nations. Rome.

Scholz, K., 2013. Carbon footprint of retail food wastage, a case study of six Swedish retail stores. Department of Energy and Technology, Swedish University of Agricultural Sciences. MSc Thesis.

Silvennoinen, K., Heikkilä, L., Katajajuuri, J.M., \& Reinikainen, A. (2015). Food waste volume and origin: Case studies in the Finnish food service sector. Waste Management, 46, 140145.

Thi, N. B. D., Lin, C.-Y., \& Kumar, G. (2016). Waste-to-wealth for valorization of food waste to hydrogen and methane towards creating a sustainable ideal source of bioenergy. Journal of Cleaner Production, 122, 29-41.

Thyberg, K. L., \& Tonjes, D. J. (2016). Drivers of food waste and their implications for sustainable policy development. Resources, Conservation and Recycling.

Wilewska-Bien, M., Granhag, L., \& Andersson, K. (2016). The nutrient load from food waste generated onboard ships in the Baltic Sea. Marine Pollution Bulletin, 105(1), 359-366 